Research Article

\title{
Anti-Inflammatory Effects of Fermented Bark of Acanthopanax sessiliflorus and Its Isolated Compounds on Lipopolysaccharide- Treated RAW 264.7 Macrophage Cells
}

\author{
Min Ji Kim, Hye Soo Wang, and Min Won Lee \\ Laboratory of Pharmacognosy and Natural Product Derived Medicine, College of Pharmacy, Chung-Ang University, \\ Seoul 06974, Republic of Korea \\ Correspondence should be addressed to Min Won Lee; mwlee@cau.ac.kr
}

Received 3 April 2020; Accepted 8 June 2020; Published 21 July 2020

Guest Editor: Xiangguo Shi

Copyright (c) 2020 Min Ji Kim et al. This is an open access article distributed under the Creative Commons Attribution License, which permits unrestricted use, distribution, and reproduction in any medium, provided the original work is properly cited.

The fermentation was carried out on the bark of Acanthopanax sessiliflorus (AS). Acanthopanax species have been used in traditional medicine as tonics, sedatives, and antispasmodics. An activity-guided isolation of the fermented bark of A. sessiliflorus (FAS) yielded several phytochemicals: acanthoside D (1), acanthoside B (2), daucosterol (3), protocatechuic acid (4), chlorogenic acid methyl ester (5), ciwujiatone (6), syringaresinol (7), farnesol (8), 3,4-dicaffeoylquinic acid (9), and falcarindiol (10). HPLC analysis showed that content of lignan glycoside (1) was decreased and 4 and 7 were increased after fermentation. Anti-inflammatory activities on FAS showed the decrease of nitric oxide (NO) production, and inhibitory activities of iNOS and COX-2, proinflammatory cytokines (IL-6 and tumor necrosis factor- $\alpha$ ), and collagenase. The aglycone, syringaresinol (7), which was increased through fermentation showed enhanced activity than $\mathbf{1}$. Thus, FAS may have the potential to treat inflammatory disorders, such as arthritis.

\section{Introduction}

Acanthopanax sessiliflorus, of the family Araliaceae, is abundant in Korea, China, Russia, and Japan. More than 30 Acanthopanax species grow in East Asia; more than 18 are known in Korea [1]. Acanthopanax species have been used in traditional medicine to make tonics, sedatives, and antispasmodics and to treat rheumatoid arthritis, diabetes, bacterial infections, cancer, and hypertension [2-4]. Various phytochemicals, such as lignans, steroids, and triterpenoidal saponins, have been identified in Acanthopanax species [5-8]. The major active component in these plants is lignan, and it has been determined that lignan plays a key role in the therapeutic effects $[9,10]$.

Various molecules are involved in the induction and maintenance of inflammatory responses. In addition to major cytokines, such as interleukin- (IL-) 1, IL-6, and tumor necrosis factor- (TNF-) $\alpha$, prostaglandin and nitric oxide (NO), which is synthesized by inducible NO synthase (iNOS), are important chemical mediators of inflammation [11]. Prostaglandin is synthesized by two cyclooxygenase (COX) isoforms, COX-1 and inducible COX-2. Therefore, the inhibition and/or downregulation of these proinflammatory molecules may exert anti-inflammatory effects in arthritis [12].

Recent studies have been conducted to enhance the physiological activity of materials by fermentation using microorganisms such as fungi, yeast, lactic acid bacteria, and mushrooms. The benefits include nonsecondary pollution, a mild reaction, and the low cost of biotransformation. Microorganisms have many bioconversion elements. As a part of our previous related work [13], inhibitory activities of nitric oxide (NO) production, iNOS and COX-2, proinflammatory cytokines (IL-6 and tumor necrosis factor- $\alpha$ ), and collagenase in lipopolysaccharide- (LPS-) treated RAW 264.7 macrophage cells were evaluated on the biotransformation product of $A$. sessiliflorus.

\section{Materials and Methods}

2.1. Plant Material. In April 2018, the bark of A. sessiliflorus was collected from Pyeongtaek, Republic of Korea, and certified by Dr. Kim (National Arboretum, Pocheon). In 
addition, a voucher specimen (201804-AS) was deposited at the herbarium of the College of Pharmacy, Chung-Ang University.

2.2. Fermentation. Lactobacillus plantarum subsp. argentoratensis was selected for this study, on the basis of a previous study [14]. L. plantarum subsp. argentoratensis was purchased from the Korean Agricultural Culture Collection (Seoul, Korea), inoculated into MRS broth, and grown at $37^{\circ} \mathrm{C}$ and $200 \mathrm{rpm}$ for $48 \mathrm{~h}$. Then, $1 \%(\mathrm{v} / \mathrm{v})$ L. plantarum subsp. argentoratensis was inoculated into MRS medium with $1 \%(\mathrm{w} / \mathrm{v})$ A. sessiliflorus extract, and fermentation was performed at $37^{\circ} \mathrm{C}$ and $200 \mathrm{rpm}$ for 5 days. After fermentation, centrifugation was performed for $20 \mathrm{~min}$ at $3000 \mathrm{rpm}$, and the supernatant was evaporated to obtain the fermented A. sessiliflorus (FAS) extract.

2.3. General Experimental Procedure. Chromatography was performed using the Sephadex LH-20 column $(10-24 \mu \mathrm{m}$; GE Healthcare Bio-Science AB, Uppsala, Sweden), MCI-gel CHP 20P (75-150 $\mu \mathrm{m}$; Mitsubishi Chemical, Tokyo, Japan), and ODS-B gel (40-60 $\mu \mathrm{m}$; Daiso, Osaka, Japan). Thin-layer chromatography (TLC) was performed using a precoated silica gel $60 \mathrm{~F}_{254}$ plate (Merck, Darmstadt, Germany) and chloroform:methanol (15:1, volume ratio) and chloroform: methanol: water $(80: 20: 2$ or $6: 4: 1)$. The spots were detected by application of a $\mathrm{FeCl}_{3}$ spray and $10 \%$ $\mathrm{H}_{2} \mathrm{SO}_{4}$ or anisaldehyde- $\mathrm{H}_{2} \mathrm{SO}_{4}$, followed by heat and $\mathrm{UV}$ irradiation $(254 \mathrm{~nm})$. The chemical structures were elucidated by using several types of instrumental analysis. 1Dnuclear magnetic resonance (NMR) experiments, such as ${ }^{1} \mathrm{H}-(600 \mathrm{MHz})$ and ${ }^{13} \mathrm{C}-(150 \mathrm{MHz}) \mathrm{NMR}$, were performed using an JNM-ECZ600R (JEOL, Massachusetts, USA) at the Center for Research facilities at Chung-Ang University.

2.4. Extraction and Isolation. The barks of A. sessiliflorus $(3.2 \mathrm{~kg})$ were extracted four times with $70 \%$ ethanol at room temperature for 3 days. The ethanol was removed under vacuum, and $143.03 \mathrm{~g}$ of the extract (AS) was obtained. Sixty grams of the extract was fermented by using $L$. plantarum subsp. Argentoratensis; the rest was stored at $-20^{\circ} \mathrm{C}$. The FAS extract was subjected to Sephadex LH-20 column chromatography and eluted with $\mathrm{MeOH}: \mathrm{H}_{2} \mathrm{O}$ gradient (from 0 : 10 to $10: 0$ ); six subfractions (fr-1 to 6) were obtained. Repeated column chromatography of fr-2 using an MCI gel column with a gradient solvent system of $\mathrm{MeOH}: \mathrm{H}_{2} \mathrm{O}$ (from $0: 10$ to $10: 0$ ) yielded $\mathbf{1}$ (acanthoside $\mathrm{D}, 119.5 \mathrm{mg}$ ), 2 (acanthoside B, 1.78g), and 3 (daucosterol, $13 \mathrm{mg}$ ). fr-3 yielded 4 (protocatechuic acid, $693.5 \mathrm{mg}$ ), 5 (chlorogenic acid methyl ester, $476.6 \mathrm{mg}$ ), 6 (ciwujiatone, $9 \mathrm{mg}$ ), 7 (syringaresinol, $890.5 \mathrm{mg}$ ), and 8 (farnesol, $1.43 \mathrm{~g}$ ). fr-4 yielded 9 (3,4-dicaffeoylquinic acid, $73 \mathrm{mg}$ ) and $\mathbf{1 0}$ (falcarindiol, $60.2 \mathrm{mg}$ ).

2.5. HPLC Analysis. The compounds in the FAS extract were compared with those in the AS extract by using highpressure liquid chromatography (HPLC). The mobile phase consisted of solvent A $\left(0.2 \%\right.$ acetic acid in $\left.\mathrm{H}_{2} \mathrm{O}\right)$ and $\mathrm{B}$ (acetonitrile (ACN); Table 1). The extracts were dissolved in $50 \% \mathrm{MeOH}$.

2.6. RAW 264.7 Cell Culture. Murine macrophage RAW 264.7 cells were purchased from the Korean Cell Line Bank (Seoul, Korea). The cells were grown in Dulbecco's modified Eagle's medium (DMEM; Welgene, Gyeongbuk, Korea) supplemented with $10 \%$ fetal bovine serum (Welgene), $100 \mathrm{IU} / \mathrm{mL}$ penicillin $\mathrm{G}$, and $100 \mathrm{mg} / \mathrm{mL}$ streptomycin (Gibco BRL, Grand Island, NY, USA) at $37^{\circ} \mathrm{C}$ in a humidified atmosphere (approximately 5\% $\mathrm{CO}_{2}$ ), and the cells were counted by using a hemocytometer.

2.7. Measurement of Cell Viability. The cytotoxicity was measured by the mitochondrial-dependent reduction of 3-(4,5-dimethylthiazol-2-yl)-2,5-diphenyltetrazoliumbromide (MTT; Sigma, St. Louis, MO, USA) to formazan. RAW 264.7 cells were seeded in 96-well plates at a density of $1 \times 10^{5}$ cells $/ \mathrm{mL}$. After incubation for $16 \mathrm{~h}$ at $37^{\circ} \mathrm{C}$, the cells were treated with $20 \mu \mathrm{L}$ of each sample in serum-free DMEM and incubated at $37^{\circ} \mathrm{C}$ in a humidified atmosphere for $24 \mathrm{~h}$. The medium was then removed, and MTT solution $(100 \mu \mathrm{L}$; $0.5 \mathrm{mg} / \mathrm{mL}$ ) was added to each well. After incubation for $4 \mathrm{~h}$, the supernatant was aspirated. The formazan crystals in each well were dissolved in $100 \mu \mathrm{L}$ dimethyl sulfoxide, and the absorbance at $540 \mathrm{~nm}$ was measured by using an enzymelinked immunosorbent assay (ELISA) plate reader (Tecan Co. Ltd., Salzburg, Australia). Relative cell viability was evaluated from the quantity of MTT converted to the insoluble formazan salt compared with distilled water as the control. The cell viability was calculated as given in the following:

$$
\text { cell viability }=\frac{\text { sample OD }}{\text { control OD }} \times 100
$$

2.8. Analysis of Inhibition of NO Production. RAW 264.7 cells $\left(2 \times 10^{5}\right.$ cells/well $)$ were seeded in 96-well plates and incubated for $16 \mathrm{~h}$ at $37^{\circ} \mathrm{C}$ in a humidified atmosphere (approximately $5 \% \mathrm{CO}_{2}$ ). The cells were incubated in a serum-free medium containing the sample and $1 \mu \mathrm{g} / \mathrm{mL}$ LPS (Sigma, St. Louis, MO, USA). After incubation for an additional $20 \mathrm{~h}$, the NO content was evaluated by using the Griess assay. The supernatant was obtained, Griess reagent (0.1\% naphthylethylenediamine and $1 \%$ sulphanilamide in $5 \% \mathrm{H}_{3} \mathrm{PO}_{4}$ solution; Sigma, St. Louis, MO, USA) was added, and the absorbance at $540 \mathrm{~nm}$ was recorded. $\mathrm{N}^{\mathrm{G}}$-monomethyl-L-arginine monoacetate salt (L-NMMA) was used as the positive control. The inhibition of NO production was calculated from equation (2). The $\mathrm{IC}_{50}$ value was defined as the concentration that inhibited $50 \%$ of NO production:

$$
\text { inhibition rate }(\%)=100-\frac{(\text { sample OD }- \text { blank OD })}{(\text { control OD }- \text { blank OD })} \times 100
$$


TABLE 1: HPLC analysis conditions.

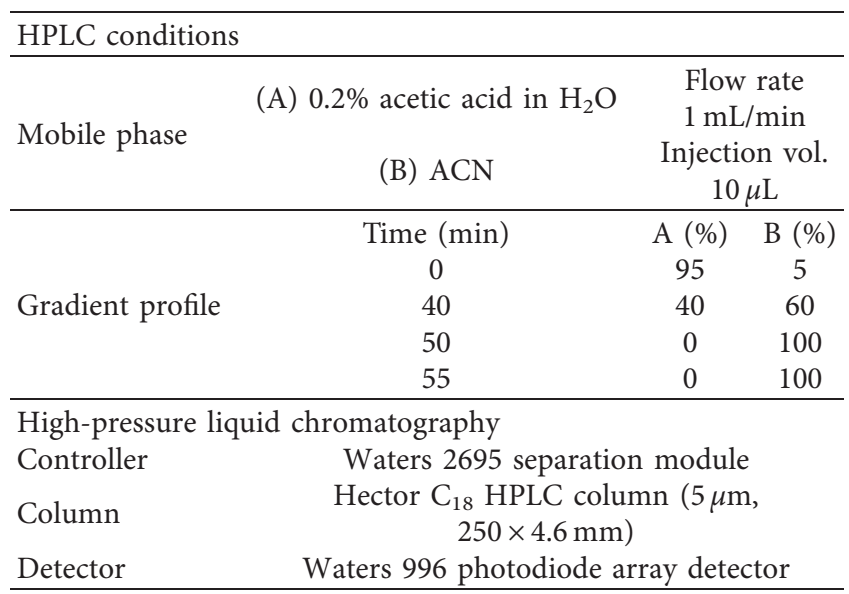

2.9. Determination of Proinflammatory Cytokine Levels. The concentrations of IL- 6 and TNF- $\alpha$ were determined by using ELISA. RAW 264.7 cells $\left(1 \times 10^{6}\right.$ cells/well $)$ were seeded in 6-well plates and preincubated for $16 \mathrm{~h}$; subsequently, the samples were treated with LPS $(1 \mu \mathrm{g} / \mathrm{mL})$ for $24 \mathrm{~h}$ to induce the production of cytokines. The supernatant was evaluated using an ELISA kit (Youngin Frontier, Seoul, Korea) in accordance with the manufacturer's instructions. The cytokine concentrations were quantified by measuring the absorbance at $450 \mathrm{~nm}$.

2.10. Western Blotting Analysis. RAW 264.7 cells $\left(1 \times 10^{6}\right.$ cells $/ \mathrm{mL}$ ) were preincubated for $16 \mathrm{~h}$ and then treated with LPS $(1 \mu \mathrm{g} / \mathrm{mL})$. After incubation for $24 \mathrm{~h}$, the cells were harvested and washed twice with phosphate-buffered saline. The cell lysates were prepared in RIPA buffer $(50 \mathrm{mM} / \mathrm{L}$ Tris-HCl [pH 7.4], 150 mM/L NaCl, 1\% Triton X-100, 0.1\% sodium dodecyl sulfate (SDS), and $1 \mathrm{mM} / \mathrm{L}$ EDTA; Thermo Fisher Scientific, MA, USA) for $30 \mathrm{~min}$ on ice. The cell lysates were centrifuged at $13,000 \times g$ for $15 \mathrm{~min}$ at $4{ }^{\circ} \mathrm{C}$, and $30 \mu \mathrm{g}$ of the cell lysate was separated by to $7.5 \%$ SDS-polyacrylamide gel electrophoresis. The separated proteins were transferred onto a PVDF membrane (Bio-Rad, CA, USA). Nonspecific binding to the membrane was blocked by incubation with blocking buffer (Thermo Fisher Scientific) for $60 \mathrm{~min}$ at room temperature. Then, the membrane was incubated with anti-mouse iNOS (1:500; Santa Cruz, CA, USA) and anti-mouse COX-2 (1:1000; BD Biosciences Pharmingen, CA, USA) overnight at $4^{\circ} \mathrm{C}$. After washing, the blots were incubated with horseradish peroxidase-conjugated goat anti-mouse IgG secondary antibody (1:1000; Santa Cruz) for $60 \mathrm{~min}$ at room temperature. The bands were visualized by using the LAS-4000 luminescent image analyzer (GE Healthcare Life Sciences, NJ, USA) and ECL detection reagent (GE Healthcare Life Sciences).

2.11. Collagenase Assay. The collagenase assay was performed as described previously [15]. Collagenase (5 $\mu \mathrm{g})$ and 4-phenylazobenzyloxycarbonyl-L-Pro-L-Leu-Gly-L-Pro-DArg $(0.5 \mathrm{mg})$, as a substrate of collagenase, were added to
$0.1 \mathrm{M}$ Tris buffer ( $\mathrm{pH} 7.4$ ) in the presence or absence of samples to a total volume of $1.7 \mathrm{~mL}$. The mixture was incubated at $37^{\circ} \mathrm{C}$ for $30 \mathrm{~min}$, and $1 \mathrm{~mL}$ of $25 \mathrm{mM}$ citric acid solution was added to terminate the enzyme reaction. Ethyl acetate $(5 \mathrm{~mL})$ was added, and the absorbance of the organic layer was measured by using UV spectrophotometry at $320 \mathrm{~nm}$ to calculate the inhibitory activity. The collagenase inhibitory activity was calculated from equation (3), where $\mathrm{OD}$ control $=\mathrm{OD}$ of the control with collagenase-OD of the control without collagenase, and OD sample $=$ OD of the test sample with collagenase-OD of the test sample without collagenase:

$$
\text { inhibition rate }(\%)=\frac{(\text { OD control }- \text { OD sample })}{\text { OD control }} \times 100 \text {. }
$$

2.12. Statistical Analysis. All data were expressed as mean \pm SD values and were evaluated by using one-way analysis of variance (ANOVA), followed by the Student-Newman-Keuls (S-N-K) test; statistical analyses were computed using Statistical Package for the Social Sciences (SPSS, Chicago, IL, USA) software package. Values were considered significantly different if the $p$ value was less than 0.05 . Different superscripts in the same column indicate that values are significantly distinct from the other data.

\section{Results and Discussion}

3.1. Isolation and Structural Identification of the Compounds. We isolated 10 compounds from FAS, namely, lignans (1, 2, $6,7)$, phenolic acids $(4,5,9)$, and others $(3,8,10)$. The isolated compounds were identified as acanthoside D (1) [16], acanthoside B (2) [17], daucosterol (3) [18], protocatechuic acid (4) [19], chlorogenic acid methyl ester (5) [20], ciwujiatone (6) [21], syringaresinol (7) [22], farnesol (8) [23, 24], 3,4-dicaffeoylquinic acid (9) [25], and falcarindiol (10) [26] through comparison of their spectral data with the values reported in other studies (Figure 1). Structures of the 10 compounds isolated from FAS were identified by analysis of ${ }^{1} \mathrm{H}$ and ${ }^{13} \mathrm{C}$ NMR spectra compared with references. ${ }^{1} \mathrm{H}$ and ${ }^{13} \mathrm{C}$ NMR spectra of the compounds (1-10) were included in Supplementary Materials as Figure S1-S10.

Acanthoside D (1): brown powder, ${ }^{1} \mathrm{H}-\mathrm{NMR}(600 \mathrm{MHz}$, DMSO-d6 + $\left.\mathrm{D}_{2} \mathrm{O}\right): \delta 6.61\left(4 \mathrm{H}, \mathrm{s}, \mathrm{H}-2^{\prime}, 6^{\prime}, 2^{\prime \prime}, 6^{\prime \prime}\right), 4.84(2 \mathrm{H}$, $\left.\mathrm{d}, J=4.2 \mathrm{~Hz}, \mathrm{H}-1^{\prime \prime \prime}, 1^{\prime \prime \prime \prime}\right), 4.63(2 \mathrm{H}, \mathrm{d}, J=3.6 \mathrm{~Hz}, \mathrm{H}-2,6), 4.16$ $(2 \mathrm{H}, \mathrm{dd}, J=9.0,6.6 \mathrm{~Hz} . \mathrm{H}-4 \beta, 8 \beta), 3.78(2 \mathrm{H}, \mathrm{dd}, J=9.0$, $3.6 \mathrm{~Hz}, \mathrm{H}-4 \alpha, 8 \alpha), 3.71$ (12H, s, H-3', $\left.5^{\prime} 3^{\prime \prime} 5^{\prime \prime}-\mathrm{OCH} 3\right), 3.54$ $\left(2 \mathrm{H}, \mathrm{m}, \mathrm{H}-6^{\prime \prime \prime} \beta, 6^{\prime \prime \prime} \beta\right), 3.36\left(2 \mathrm{H}, \mathrm{dd}, J=6,12.0 \mathrm{~Hz}, \mathrm{H}-6^{\prime \prime \prime} \alpha\right.$, $\left.6^{\prime \prime \prime} \beta\right), 3.17-3.04\left(8 \mathrm{H}, \mathrm{m}, 2^{\prime \prime \prime}, 3^{\prime \prime \prime}, 4^{\prime \prime \prime}, 5^{\prime \prime \prime}, 2^{\prime \prime \prime \prime}, 3^{\prime \prime \prime \prime}, 4^{\prime \prime \prime \prime}, 5^{\prime \prime \prime \prime}\right)$, 3.10-3.07 (2H, m, H-1, 5); ${ }^{13} \mathrm{C}-\mathrm{NMR}$ (150 MHz, DMSO$\left.\mathrm{d} 6+\mathrm{D}_{2} \mathrm{O}\right): \delta 153.1\left(\mathrm{C}-3^{\prime}, 5^{\prime}, 3^{\prime \prime}, 5^{\prime \prime}\right), 137.7\left(\mathrm{C}-4^{\prime}, 4^{\prime \prime}\right), 134.2$ $\left(\mathrm{C}-1^{\prime}, 1^{\prime \prime}\right), 104.7\left(\mathrm{C}-2^{\prime}, 6^{\prime}, 2^{\prime \prime}, 6^{\prime \prime}\right), 103.2\left(\mathrm{C}-1^{\prime \prime \prime}, 1^{\prime \prime \prime \prime}\right), 85.6$ (C-2, 6), $77.6\left(\mathrm{C}-5^{\prime \prime \prime}, 5^{\prime \prime \prime \prime}\right), 76.9\left(\mathrm{C}-3^{\prime \prime \prime}, 3^{\prime \prime \prime \prime}\right), 74.6$ (C-2 ${ }^{\prime \prime \prime}$, $\left.2^{\prime \prime \prime \prime}\right), 71.9(\mathrm{C}-4,8), 70.3\left(\mathrm{C}-4^{\prime \prime \prime}, 4^{\prime \prime \prime}\right), 61.3\left(\mathrm{C}-6^{\prime \prime \prime}, 6^{\prime \prime \prime \prime}\right), 56.9$ $\left(\mathrm{C}-3^{\prime}, 5^{\prime}, 3^{\prime \prime}, 5^{\prime \prime}-\mathrm{OCH} 3\right), 54.1(\mathrm{C}-1,5)$. 


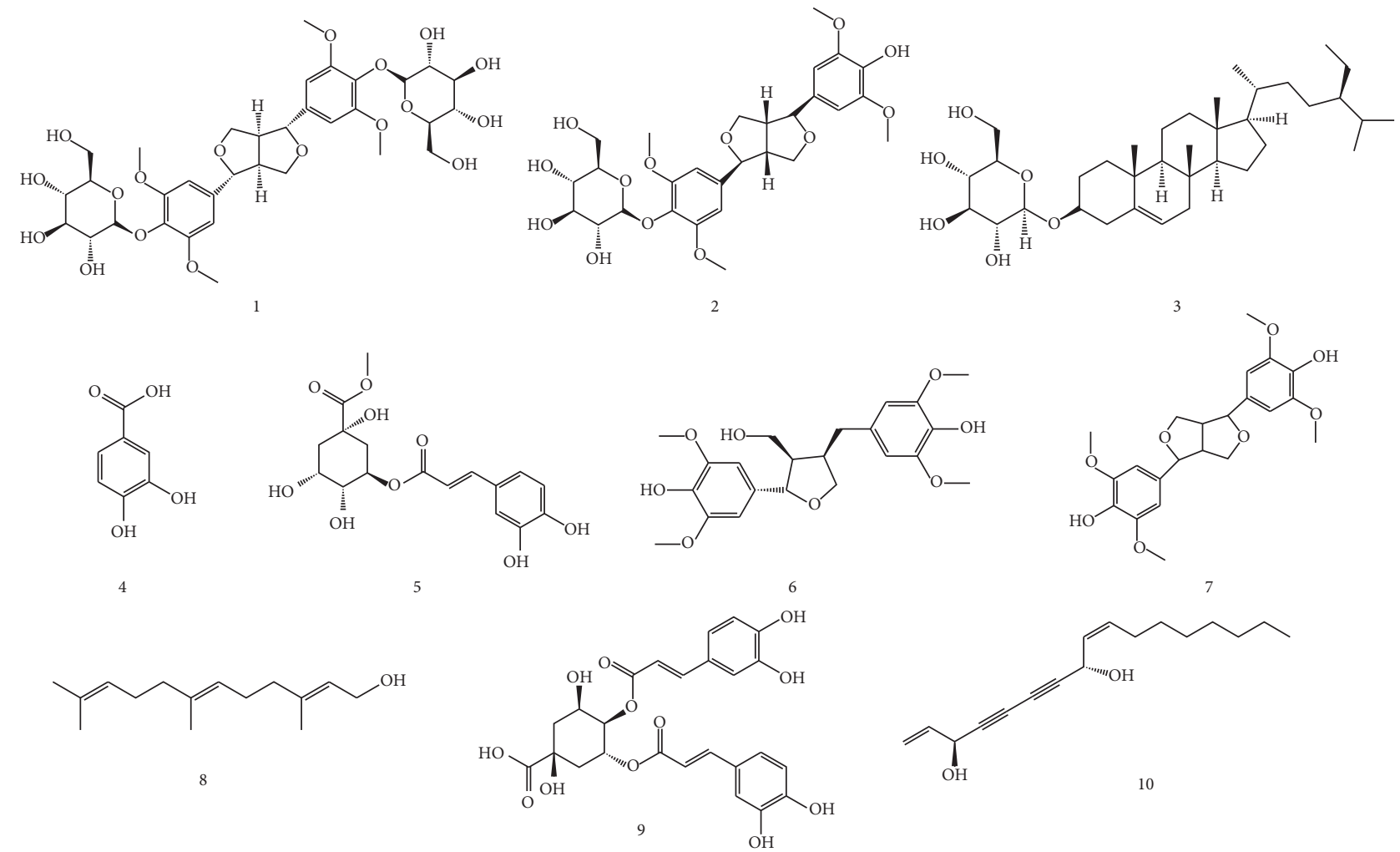

Figure 1: Structures of compounds 1-10.

Acanthoside B (2): brown powder, ${ }^{1} \mathrm{H}-\mathrm{NMR}(600 \mathrm{MHz}$, DMSO-d $\left.6+\mathrm{D}_{2} \mathrm{O}\right): \delta 6.61\left(2 \mathrm{H}, \mathrm{s}, \mathrm{H}-2^{\prime \prime}, 6^{\prime \prime}\right), 6.55\left(2 \mathrm{H}, \mathrm{s}, \mathrm{H}-2^{\prime}\right.$, $\left.6^{\prime}\right), 4.83\left(1 \mathrm{H}, \mathrm{m}, \mathrm{H}-1^{\prime \prime \prime}\right), 4.63(1 \mathrm{H}, \mathrm{d}, J=4.8 \mathrm{~Hz}, \mathrm{H}-2), 4.57$ $(1 \mathrm{H}, \mathrm{d}, J=4.2, \mathrm{H}-6), 4.13(2 \mathrm{H}, \mathrm{m}, \mathrm{H}-4 \beta, 8 \beta), 3.75(2 \mathrm{H}, \mathrm{dd}$, $J=5.4,3.6 \mathrm{~Hz}, \mathrm{H}-4 \alpha, 8 \alpha), 3.71\left(6 \mathrm{H}, \mathrm{s}, \mathrm{OCH} 3-3^{\prime \prime}, 5^{\prime \prime}\right), 3.70$ $\left(6 \mathrm{H}, \mathrm{s}, \mathrm{OCH} 3-3^{\prime}, 5^{\prime}\right), 3.54\left(1 \mathrm{H}, \mathrm{dd}, J=12.0,1.8 \mathrm{~Hz}, \mathrm{H}-6^{\prime \prime \prime} \alpha\right)$, $3.60\left(1 \mathrm{H}, \mathrm{m}, \mathrm{H}-6^{\prime \prime \prime} \beta\right), 3.16\left(2 \mathrm{H}, \mathrm{m}, \mathrm{H}-2^{\prime \prime \prime}, 3^{\prime \prime \prime}\right), 3.10(1 \mathrm{H}, \mathrm{m}$, $\left.4^{\prime \prime \prime}\right), 3.01(2 \mathrm{H}, \mathrm{m}, \mathrm{H}-1,5), 2.99\left(1 \mathrm{H}, \mathrm{H}-5^{\prime \prime \prime}\right) ;{ }^{13} \mathrm{C}-\mathrm{NMR}$ $\left(150 \mathrm{MHz}, \mathrm{DMSO}-\mathrm{d} 6+\mathrm{D}_{2} \mathrm{O}\right): \delta 153.1\left(\mathrm{C}-3^{\prime}, 5^{\prime}\right), 148.3\left(\mathrm{C}-3^{\prime \prime}\right.$, $\left.5^{\prime \prime}\right), 137.8\left(\mathrm{C}-1^{\prime}\right), 135.2\left(\mathrm{C}-4^{\prime \prime}\right), 134.1\left(\mathrm{C}-4^{\prime}\right), 131.9\left(\mathrm{C}-1^{\prime \prime}\right)$, $104.6\left(\mathrm{C}-2^{\prime}, 6^{\prime}\right), 104.1\left(\mathrm{C}-2^{\prime \prime}, 6^{\prime \prime}\right), 103.2\left(\mathrm{C}-1^{\prime \prime \prime}\right), 85.9(\mathrm{C}-6)$, 85.6 (C-2), $77.6\left(\mathrm{C}-5^{\prime \prime \prime}\right), 76.8\left(\mathrm{C}-3^{\prime \prime \prime}\right), 74.5\left(\mathrm{C}-2^{\prime \prime \prime}\right), 71.8(\mathrm{C}-8)$, 71.7 (C-4), 70.3 (C-4'"'), 60.6 (C-6'"'), 56.9 (C-3', 5'-OCH3), 56.5 (C-3" $\left.3^{\prime \prime}, 5^{\prime \prime}-\mathrm{OCH} 3\right), 54.2$ (C-1), 54.1 (C-5).

Daucosterol (3): white powder, ${ }^{13} \mathrm{C}-\mathrm{NMR}(150 \mathrm{MHz}$, pyridine-d5): $\delta 140.7$ (C-5), 121.8 (C-6), $102.4\left(\mathrm{C}-1^{\prime}\right), 78.5$ (C-3), $78.4\left(\mathrm{C}-3^{\prime}\right), 77.9\left(\mathrm{C}-5^{\prime}\right), 75.2\left(\mathrm{C}-2^{\prime}\right), 71.5\left(\mathrm{C}-4^{\prime}\right), 62.7\left(\mathrm{C}-6^{\prime}\right), 56.7$ (C-14), 56.1 (C-17), 50.2 (C-9), 45.9 (C-24), 42.3 (C-13), 39.8 (C-4), 39.2 (C-12), 37.3 (C-1), 36.8 (C-10), 36.2 (C-20), 34.0 (C-22), 32.0 (C-7), 31.9 (C-8), 30.1 (C-2), 29.3 (C-25), 28.4 (C-16), 26.2 (C-23), 24.4 (C-15), 23.2 (C-28), 21.1 (C-11), 19.8 (C-27), 19.3 (C-19), 19.0 (C-26), 18.9 (C-21), 12.0 (C-29), 11.8 (C-18).

Protocatechuic acid (4): brown needle, ${ }^{1} \mathrm{H}-\mathrm{NMR}$ $\left(600 \mathrm{MHz}, \mathrm{DMSO}-\mathrm{d} 6+\mathrm{D}_{2} \mathrm{O}\right): \delta 7.29(1 \mathrm{H}, \mathrm{d}, J=1.8 \mathrm{~Hz}, \mathrm{H}-2)$, $7.25(1 \mathrm{H}, \mathrm{dd}, J=8.4,1.8 \mathrm{~Hz}, \mathrm{H}-6), 6.75(1 \mathrm{H}, \mathrm{d}, J=8.4 \mathrm{~Hz}$, $\mathrm{H}-5) ;{ }^{13} \mathrm{C}-\mathrm{NMR}\left(150 \mathrm{MHz}\right.$, DMSO-d6 + $\left.\mathrm{D}_{2} \mathrm{O}\right): \delta 167.9(\mathrm{C}-7)$, 150.3 (C-4), 145.2 (C-3), 122.5 (C-1), 122.1 (C-6), 117.0 (C-2), 115.6 (C-5).

Chlorogenic acid methyl ester (5): brown powder, ${ }^{1} \mathrm{H}-\mathrm{NMR}\left(600 \mathrm{MHz}\right.$, DMSO-d6 + $\left.\mathrm{D}_{2} \mathrm{O}\right): \delta 7.32(1 \mathrm{H}, \mathrm{d}$,
$\left.J=16.2 \mathrm{~Hz}, \mathrm{H}^{\prime} 7^{\prime}\right), 6.99\left(1 \mathrm{H}, \mathrm{d}, J=2.4 \mathrm{~Hz}, \mathrm{H}-2^{\prime}\right), 6.92(1 \mathrm{H}, \mathrm{dd}$, $\left.J=8.4,2.4 \mathrm{~Hz}, \mathrm{H}-6^{\prime}\right), 6.73\left(1 \mathrm{H}, \mathrm{d}, J=8.4 \mathrm{~Hz}, \mathrm{H}-5^{\prime}\right), 6.07(1 \mathrm{H}$, d, $\left.J=16.2 \mathrm{~Hz}, \mathrm{H}-8^{\prime}\right), 4.96(1 \mathrm{H}, \mathrm{dd}, J=9.6,5.4 \mathrm{~Hz}, \mathrm{H}-3), 3.83$ $(1 \mathrm{H}, \mathrm{dt}, J=9.0,3.6, \mathrm{H}-5), 3.50(3 \mathrm{H}, \mathrm{s}, \mathrm{H}-\mathrm{CH} 3), 2.05(2 \mathrm{H}, \mathrm{m}$, $\mathrm{H}-2 \alpha, 2 \beta), 1.80(1 \mathrm{H}, \mathrm{m}, \mathrm{H}-6 \alpha), 1.71(1 \mathrm{H}, \mathrm{m}, \mathrm{H}-6 \beta) ;{ }^{13} \mathrm{C}-\mathrm{NMR}$ $\left(150 \mathrm{MHz}\right.$, DMSO-d6 + $\left.\mathrm{D}_{2} \mathrm{O}\right): \delta 174.1(\mathrm{C}-7), 166.0\left(\mathrm{C}-9^{\prime}\right)$, $148.8\left(\mathrm{C}-4^{\prime}\right), 145.9\left(\mathrm{C}-3^{\prime}\right), 145.7\left(\mathrm{C}-7^{\prime}\right), 126.0\left(\mathrm{C}-1^{\prime}\right), 122.0$ $\left(\mathrm{C}-6^{\prime}\right), 116.3\left(\mathrm{C}-2^{\prime}\right), 114.9\left(\mathrm{C}-5^{\prime}\right), 114.4\left(\mathrm{C}-8^{\prime}\right), 73.5(\mathrm{C}-1)$, 71.5 (C-5), 69.7 (C-4), 52.4 (C-CH3), 37.6 (C-6), 35.5 (C-2).

Ciwujiatone (6): yellowish powder, ${ }^{1} \mathrm{H}-\mathrm{NMR}(600 \mathrm{MHz}$, DMSO-d6 + $\left.\mathrm{D}_{2} \mathrm{O}\right): \delta 7.25(2 \mathrm{H}, \mathrm{s}, \mathrm{H}-2,6), 6.56\left(2 \mathrm{H}, \mathrm{s}, \mathrm{H}-2^{\prime}\right.$, $\left.6^{\prime}\right), 4.49\left(1 \mathrm{H}, \mathrm{d}, J=7.8 \mathrm{~Hz}, \mathrm{H}-7^{\prime}\right), 4.13(1 \mathrm{H}, \mathrm{m}, \mathrm{H}-8), 4.02(2 \mathrm{H}$, m, H-9), $3.78(6 \mathrm{H}, \mathrm{s}, \mathrm{H}-3,5-\mathrm{OCH} 3), 3.40\left(6 \mathrm{H}, \mathrm{s}, \mathrm{H}-3^{\prime}, 5^{\prime}-\right.$ OCH3), $3.46\left(2 \mathrm{H}, \mathrm{m}, \mathrm{H}-9^{\prime}\right), 2.43(1 \mathrm{H}, \mathrm{m}, \mathrm{H}-8) ;{ }^{13} \mathrm{C}-\mathrm{NMR}$ $\left(150 \mathrm{MHz}, \mathrm{DMSO}-\mathrm{d} 6+\mathrm{D}_{2} \mathrm{O}\right): \delta 198.8(\mathrm{C}-7), 148.2\left(\mathrm{C}-3^{\prime}, 5^{\prime}\right)$, $148.2(\mathrm{C}-3,5), 141.9(\mathrm{C}-4), 135.1\left(\mathrm{C}-4^{\prime}\right), 132.4\left(\mathrm{C}-1^{\prime}\right), 127.4$ (C-1), 106.9 (C-2, 6), 104.4 (C-2', 6'), $83.6\left(\mathrm{C}-7^{\prime}\right), 70.3(\mathrm{C}-9)$, $60.3\left(\mathrm{C}-9^{\prime}\right), 56.6(\mathrm{C}-3), 56.6(\mathrm{C}-5), 56.5\left(\mathrm{C}-3^{\prime}, 5^{\prime}\right), 56.0$ (C$\left.8^{\prime}\right), 49.0$ (C-8).

Syringaresinol (7): light brown powder, ${ }^{1} \mathrm{H}-\mathrm{NMR}$ $\left(600 \mathrm{MHz}, \mathrm{CDCl}_{3}\right): \delta 6.57\left(4 \mathrm{H}, \mathrm{s}, \mathrm{H}-2^{\prime \prime}, 6^{\prime \prime}, 2^{\prime \prime \prime}, 6^{\prime \prime \prime}\right), 4.71$ $(2 \mathrm{H}, \mathrm{m}, \mathrm{H}-2,6), 4.27(2 \mathrm{H}, \mathrm{m}, \mathrm{H}-4 \alpha, 8 \alpha), 3.89(2 \mathrm{H}, \mathrm{m}, \mathrm{H}-4 \beta$, $8 \beta), 3.88\left(12 \mathrm{H}, \mathrm{s}, \mathrm{H}-3^{\prime \prime}, 5^{\prime \prime}, 3^{\prime \prime \prime}, 5^{\prime \prime \prime}-\mathrm{OCH} 3\right), 3.08$ (2H, m, H-1, 5); ${ }^{13} \mathrm{C}-\mathrm{NMR}\left(150 \mathrm{MHz}, \mathrm{CDCl}_{3}\right): \delta 147.2\left(\mathrm{C}-3^{\prime}, 5^{\prime}\right), 134.3(\mathrm{C}-$ $\left.4^{\prime}\right), 132.2\left(\mathrm{C}-1^{\prime}\right), 102.7\left(\mathrm{C}-2^{\prime}, 6^{\prime}\right), 86.2(\mathrm{C}-2,6), 71.9(\mathrm{C}-4,8)$, $56.5\left(\mathrm{C}-3^{\prime \prime}, 5^{\prime \prime}, 3^{\prime \prime \prime}, 5^{\prime \prime \prime}-\mathrm{OCH} 3\right), 54.4(\mathrm{C}-1,5)$.

Farnesol (8): yellowish oil, ${ }^{1} \mathrm{H}-\mathrm{NMR}\left(600 \mathrm{MHz}, \mathrm{CDCl}_{3}\right)$ : $\delta 5.39(1 \mathrm{H}, \mathrm{t}, J=7.2 \mathrm{~Hz}, \mathrm{H}-2), 5.13(2 \mathrm{H}, \mathrm{m}, \mathrm{H}-6,10), 4.13(2 \mathrm{H}$, d, $J=7.2 \mathrm{~Hz}, \mathrm{H}-1), 2.10-1.95(4 \mathrm{H}, \mathrm{m}, \mathrm{H}-4,5,8,9), 1.65(6 \mathrm{H}$, brs, $\mathrm{H}-12,15), 1.58$ (6H, brs, $\mathrm{H}-13,14) ;{ }^{13} \mathrm{C}-\mathrm{NMR}(150 \mathrm{MHz}$, 


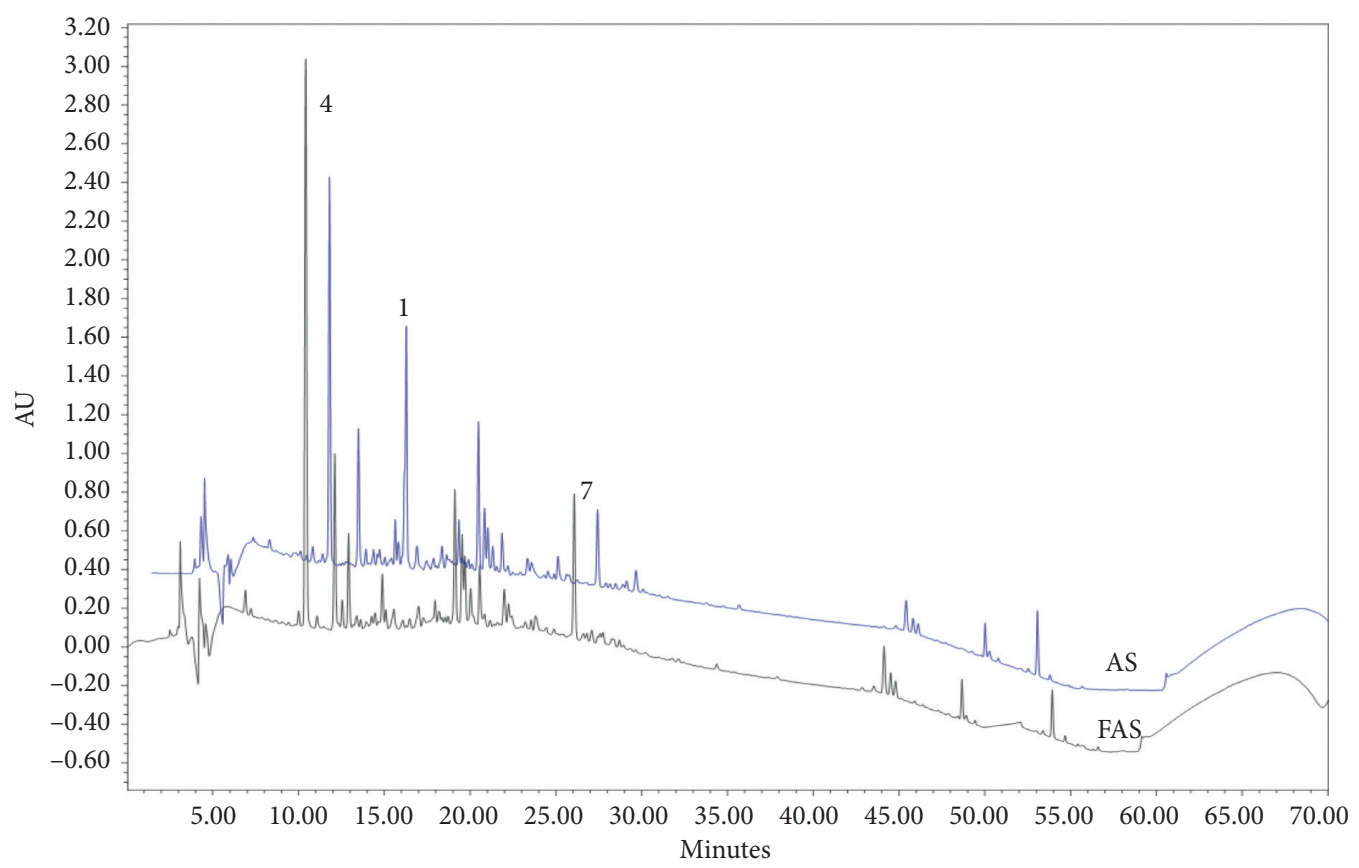

FIgURE 2: HPLC peaks for comparison of FAS and AS.

$\left.\mathrm{CDCl}_{3}\right): \delta 139.9(\mathrm{C}-3), 135.4(\mathrm{C}-7), 131.4(\mathrm{C}-11), 124.4(\mathrm{C}-$ 10), 123.9 (C-6), 123.3 (C-2), 59.4 (C-1), 39.8 (C-8), 39.6 (C4), 26.8 (C-9), 26.4 (C-5), 25.8 (C-12), 17.8 (C-15), 16.4 (C13), 16.1 (C-14).

3,4-dicaffeoylquinic acid (9): brown powder, ${ }^{1} \mathrm{H}-\mathrm{NMR}$ $\left(600 \mathrm{MHz}, \mathrm{CD}_{3} \mathrm{OD}+\mathrm{D}_{2} \mathrm{O}\right): \delta 7.57\left(1 \mathrm{H}, \mathrm{d}, J=15.6 \mathrm{~Hz}, \mathrm{H}-7^{\prime}\right)$, $7.49\left(1 \mathrm{H}, \mathrm{d}, J=16.2 \mathrm{~Hz}, \mathrm{H}-7^{\prime \prime}\right), 7.00\left(2 \mathrm{H}, \mathrm{m}, \mathrm{H}-2^{\prime}, 2^{\prime \prime}\right), 6.88$ $\left(2 \mathrm{H}, \mathrm{dd}, J=8.4,1.2 \mathrm{~Hz}, \mathrm{H}-6^{\prime}, 6^{\prime \prime}\right), 6.73(1 \mathrm{H}, \mathrm{d}, J=8.4 \mathrm{~Hz}$, $\left.\mathrm{H}-5^{\prime}, 5^{\prime \prime}\right), \quad 6.27\left(1 \mathrm{H}, \mathrm{d}, J=15.6 \mathrm{~Hz}, \mathrm{H}-8^{\prime}\right), \quad 6.17(1 \mathrm{H}, \mathrm{d}$, $\left.J=15.6 \mathrm{~Hz}, \mathrm{H}-8^{\prime \prime}\right), 5.61$ (1H, m, H-3), 5.09 (1H, m, H-4), 3.36 $(1 \mathrm{H}, \mathrm{m}, \mathrm{H}-5), \quad 2.50-2.02(4 \mathrm{H}, \mathrm{m}, \mathrm{H}-2,6) ;{ }^{13} \mathrm{C}-\mathrm{NMR}$ $\left(150 \mathrm{MHz}, \mathrm{CD}_{3} \mathrm{OD}+\mathrm{D}_{2} \mathrm{O}\right): \delta 174.0(\mathrm{C}-7), 167.4\left(\mathrm{C}-9^{\prime}\right), 167.1$ $\left(\mathrm{C}-9^{\prime \prime}\right), 148.3\left(\mathrm{C}-4^{\prime}, 4^{\prime \prime}\right), 146.5\left(\mathrm{C}-7^{\prime}\right), 146.4\left(\mathrm{C}-7^{\prime \prime}\right), 145.3$ $\left(\mathrm{C}-3^{\prime}\right), 145.3\left(\mathrm{C}-3^{\prime \prime}\right), 126.4\left(\mathrm{C}-1^{\prime}\right), 126.3\left(\mathrm{C}-1^{\prime \prime}\right), 122.0\left(\mathrm{C}-6^{\prime}\right)$, $122.0\left(\mathrm{C}-6^{\prime \prime}\right), 115.2\left(\mathrm{C}-5^{\prime}, 5^{\prime \prime}\right), 113.9\left(\mathrm{C}-2^{\prime}, 2^{\prime \prime}\right), 113.4\left(\mathrm{C}-8^{\prime}\right)$, $113.4\left(\mathrm{C}-8^{\prime \prime}\right), 74.6(\mathrm{C}-1), 74.5$ (C-4), 68.6 (C-5), 67.8 (C-3), 37.2 (C-2), 37.0 (C-6).

Falcarindiol (10): brown oil, ${ }^{1} \mathrm{H}-\mathrm{NMR}\left(600 \mathrm{MHz}, \mathrm{CDCl}_{3}\right)$ : $\delta 5.92(1 \mathrm{H}, \mathrm{ddd}, J=16.8,10.2,5.4 \mathrm{~Hz}, \mathrm{H}-2), 5.60(1 \mathrm{H}, \mathrm{ddt}$, $J=10.8,7.8,1.2 \mathrm{~Hz}, \mathrm{H}-10), 5.50(2 \mathrm{H}, \mathrm{m}, \mathrm{H}-1 \alpha, 9), 5.25(1 \mathrm{H}, \mathrm{m}$, $\mathrm{H}-1 \beta), 5.20(1 \mathrm{H}, \mathrm{d}, J=7.8 \mathrm{~Hz}, \mathrm{H}-8), 4.93(1 \mathrm{H}$, brd, $J=5.4 \mathrm{~Hz}$, $\mathrm{H}-3), 2.10$ (2H, m, H-11), 1.37 (2H, m, H-12), 1.25 (8H, m, $\mathrm{H}-13,14,15,16) 0.87$ (3H, t-like, $J=7.5 \mathrm{~Hz}, \mathrm{H}-17)$; ${ }^{13} \mathrm{C}-\mathrm{NMR}$ $\left(150 \mathrm{MHz}, \mathrm{CDCl}_{3}\right): \delta 135.9(\mathrm{C}-2), 134.8$ (C-10), 127.7 (C-9), 117.4 (C-1), 79.9 (C-7), 78.3 (C-4), 70.4 (C-5), 68.8 (C-6), 63.6 (C-3), 58.7 (C-8), 31.9 (C-15), 31.0 (C-13), 29.4 (C-14), 29.2 (C-12), 27.8 (C-11), 22.7 (C-16), 14.2 (C-17).

3.2. HPLC Analysis Results. The compounds in the FAS were compared with AS by using HPLC. In this study, the remarkable differences were found in the contents of several compounds that acanthoside D (1) was lower and syringaresinol (7) and protocatechuic acid (4) were higher in FAS than in AS (Figure 2, Table 2).
TABLE 2: Retention time and percentage of compounds $\mathbf{1}, \mathbf{4}$, and 7 in AS and FAS.

\begin{tabular}{lccc}
\hline Compound & Retention time $(\mathrm{min})$ & AS (\%) & FAS (\%) \\
\hline $\mathbf{1}$ & 14.9 & 13.67 & 2.19 \\
$\mathbf{4}$ & 10.4 & 1.68 & 3.50 \\
$\mathbf{7}$ & 26.1 & 4.45 & 9.94 \\
\hline
\end{tabular}

3.3. Cell Viability. Prior to the biological assays, the MTT assays were performed using the extracts and each compound from the FAS extract. The extracts and compounds did not affect the cell viability $(>80 \%)$ at the experimental doses (Figure 3 ). These results demonstrated that the concentration used in the inhibition experiments of the production of $\mathrm{NO}$ and cytokines and inflammatory molecules by the extracts and compounds was not cytotoxic.

To assess the anti-inflammatory activity of AS, FAS, and compounds 1-10 isolated from FAS, the inhibitory effects on NO production in RAW 264.7 cells were evaluated. FAS $\left(\mathrm{IC}_{50}=\right.$ $12.31 \pm 0.92 \mu \mathrm{g} / \mathrm{mL}$ ) had strong inhibitory effects on NO production compared with AS $\left(\mathrm{IC}_{50}=26.56 \pm 1.28 \mu \mathrm{g} / \mathrm{mL}\right)$ and effects similar to those of the positive control, L-NMMA $\left(\mathrm{IC}_{50}=10.16 \pm 0.85 \mu \mathrm{g} / \mathrm{mL}\right)$. Most of the isolated compounds had strong inhibitory effects on NO production (Table 3). Some compounds isolated from FAS, 7 ( $\left.\mathrm{IC}_{50}=26.56 \pm 1.28 \mu \mathrm{M}\right), 8$ $\left(\mathrm{IC}_{50}=40.63 \pm 3.38 \mu \mathrm{M}\right), 9 \quad\left(\mathrm{IC}_{50}=7.95 \pm 2.03 \mu \mathrm{M}\right)$, and $\mathbf{1 0}$ $\left(\mathrm{IC}_{50}=21.87 \pm 1.02 \mu \mathrm{M}\right)$, more strongly inhibited NO production than the positive control, L-NMMA ( $\left.\mathrm{IC}_{50}=19.68 \pm 5.38 \mu \mathrm{M}\right)$. In particular, the aglycone form (7) showed better activity than the glycoside (1).

3.4. Inhibition of iNOS and COX-2 Levels. To further characterize the mechanisms underlying the inhibition of the LPS-induced production of $\mathrm{NO}$ by the extracts and 


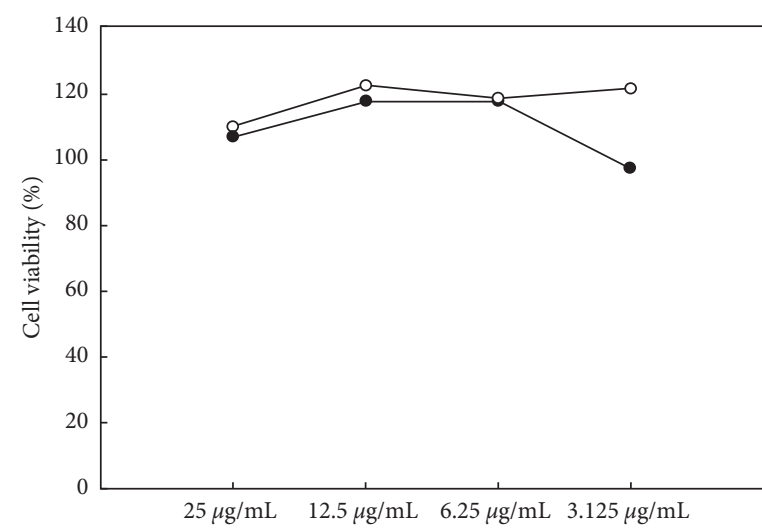

(a)

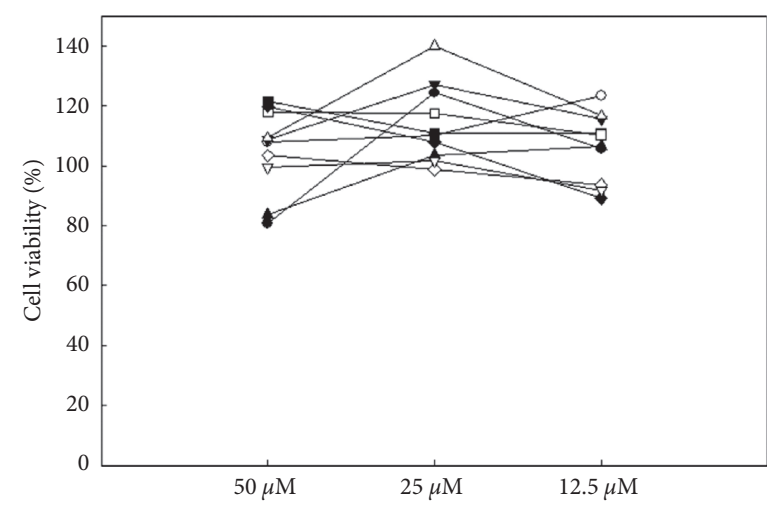

(b)

FIgUre 3: Cell viability assay. (a) Effects of AS (O) and FAS (๑) extracts on the viability of RAW 264.7 cells. (b) Effects of compounds $\mathbf{1 - 1 0}$ on the viability of RAW 264.7 cells. $1(\bullet), 2(\bigcirc), 3(\nabla), 4(\triangle), 5(\square), 6(\square), 7(\diamond), 8(\diamond), 9(\Delta)$, and $10(\nabla)$.

TABLE 3: $\mathrm{IC}_{50}$ values for inhibition of NO production by AS, FAS, and isolated compounds 1-10.

\begin{tabular}{|c|c|c|c|}
\hline Extract & $\mathrm{IC}_{50}(\mu \mathrm{g} / \mathrm{mL})$ & Compound & $\mathrm{IC}_{50}(\mu \mathrm{M})$ \\
\hline AS & $26.56 \pm 1.28^{\mathrm{b}}$ & 1 & $57.71 \pm 2.33^{\mathrm{c}}$ \\
\hline FAS & $12.37 \pm 0.92^{\mathrm{a}}$ & 2 & $>100^{\mathrm{e}}$ \\
\hline \multirow[t]{9}{*}{ L-NMMA } & $10.16 \pm 0.85^{\mathrm{a}}$ & 3 & $>100^{\mathrm{d}}$ \\
\hline & & 4 & $40.63 \pm 3.38^{b, c}$ \\
\hline & & 5 & $45.80 \pm 8.28^{\mathrm{b}, \mathrm{c}}$ \\
\hline & & 6 & $>100^{\mathrm{d}}$ \\
\hline & & 7 & $26.16 \pm 1.37^{\mathrm{a}, \mathrm{b}}$ \\
\hline & & 8 & $37.35 \pm 7.97^{\mathrm{b}, \mathrm{c}}$ \\
\hline & & 9 & $7.95 \pm 2.03^{\mathrm{a}}$ \\
\hline & & 10 & $21.87 \pm 1.02^{\mathrm{a}, \mathrm{b}}$ \\
\hline & & L-NMMA & $19.68 \pm 5.38^{\mathrm{a}, \mathrm{b}}$ \\
\hline
\end{tabular}

Values are expressed as the mean \pm SD of triplicate experiments. Values with different superscripts $(\mathrm{a}-\mathrm{e})$ in the same columns are significantly different $(p<0.05)$.

compounds, western blotting assays were performed. Four compounds (7-10) that showed strong inhibitory activity in the NO production assay were selected for the test of iNOS and COX-2; in addition, compound $\mathbf{1}$ was selected for comparison with its aglycone, 7. The levels of iNOS and COX-2 were significantly increased in the LPS-stimulated cells compared with the control cells (Figure 4). Treatment with AS, FAS, and the selected compounds significantly inhibited iNOS expression in a concentration-dependent manner; similar results were obtained for COX-2. The FAS extract strongly inhibited iNOS and COX-2 levels compared with AS. Most of the compounds decreased iNOS and COX2 production, especially 9 and 10, and the aglycone (7) showed better activity than the glycoside (1). These results indicated that the extracts and compounds inhibited $\mathrm{NO}$ production through a decrease in iNOS and COX-2 expression in the LPS-stimulated RAW 264.7 cells.

3.5. Effects on Cytokine Production. The inhibition of cytokine (IL- 6 and TNF- $\alpha$ ) production was analyzed by using ELISA. RAW 264.7 macrophage cells were exposed to LPS, and the cytokine levels in these cells were measured for their evaluation of the inhibitory effects of AS, FAS, and the isolated compounds. In the LPS-treated group (control), IL6 and TNF- $\alpha$ levels were detected to be $548.12 \mathrm{pg} / \mathrm{mL}$ and $777.89 \mathrm{pg} / \mathrm{mL}$, respectively. In the AS and FAS treated groups, IL-6 and TNF- $\alpha$ levels were decreased (Figures 5(a) and 5(b)). The FAS inhibited cytokines to a greater extent than AS did. RAW 264.7 cells were exposed to LPS, and the inhibitory effects of compounds (1 and 7-10) on cytokine production (IL-6 and TNF- $\alpha$ ) were measured. In the LPStreated group (control), IL-6 and TNF- $\alpha$ levels were 262.07 $\mathrm{pg} / \mathrm{mL}$ and $302.88 \mathrm{pg} / \mathrm{mL}$, respectively. IL-6 and TNF- $\alpha$ levels were decreased by treatment with the selected compounds. And the 9, 10, and the aglycone 7 showed better activity than the glycoside (Figures 5(c) and 5(d)).

3.6. Effects on Collagenase Reaction. The inhibition of collagenase by AS, FAS, and the isolated compounds was evaluated. FAS (79\%) more strongly inhibited collagenase when compared with AS (33\%; Table 4). The effects of five compounds (1 and 7-10) on the collagenase reaction were measured. Compounds 9 (90.38\%) and 10 (52.88\%) showed potent inhibitory activities, and 1, 7, and $\mathbf{8}$ exhibited moderate activities. The aglycone form (7) (23.08\%) showed better activity than the glycoside form (1) (15.38\%). 


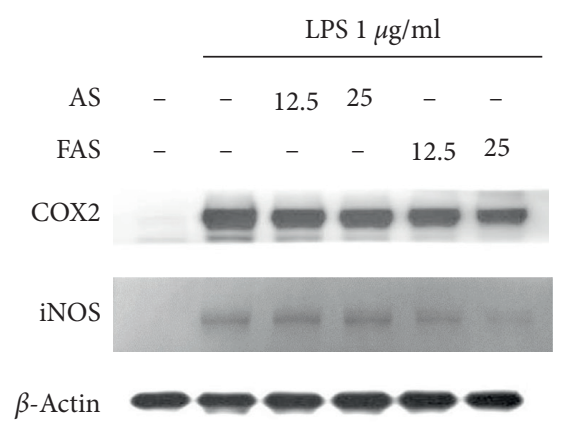

(a)

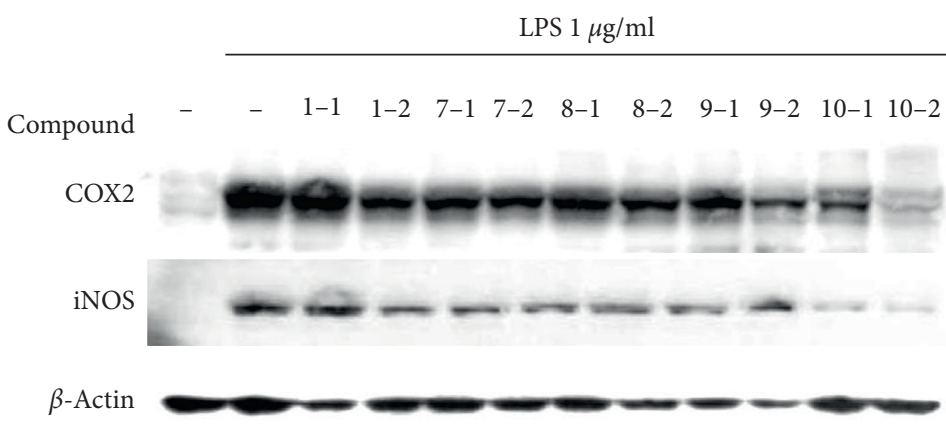

(b)

FIgURE 4: Expression of iNOS and COX-2 (western blotting). (a) Effects of AS and FAS on the expression of iNOS and COX-2 in the LPSstimulated RAW 264.7 cells. 12.5, $12.5 \mu \mathrm{g} / \mathrm{mL} ; 25,25 \mu \mathrm{g} / \mathrm{mL}$. (b) Effects of the selected compounds on the expression of iNOS and COX-2 in the LPS-stimulated RAW 264.7 cells. $1,50 \mu \mathrm{M} ; 2,25 \mu \mathrm{M}$.

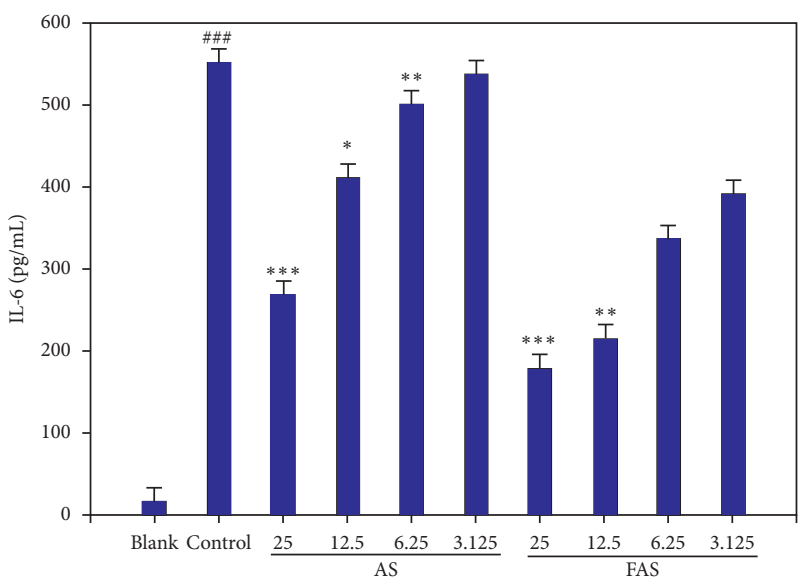

(a)

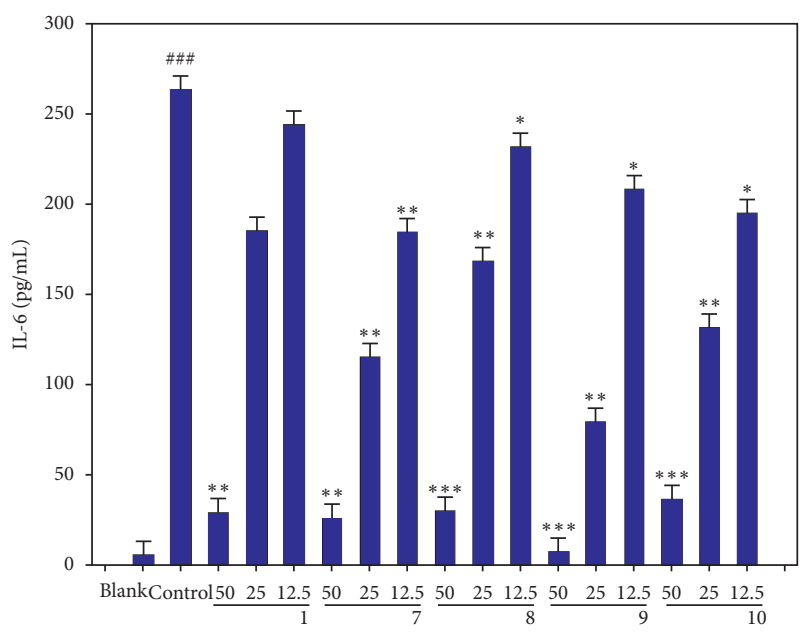

(c)

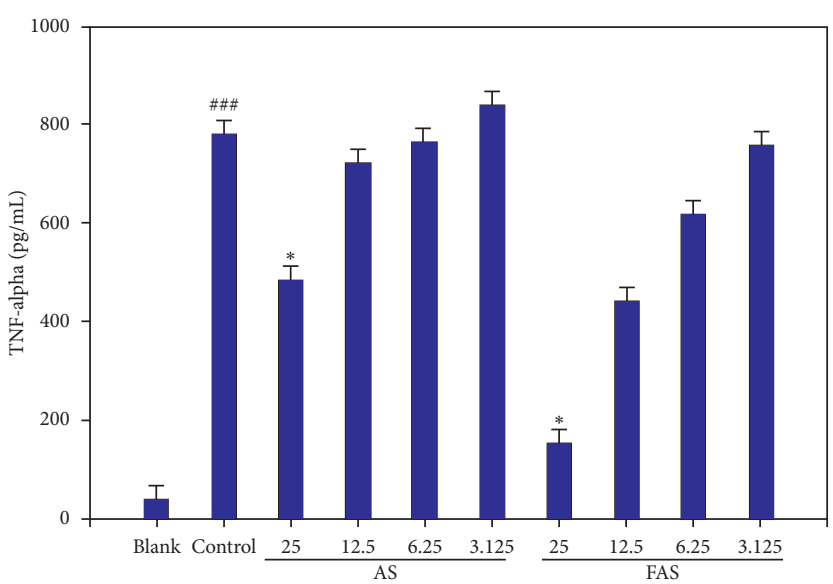

(b)

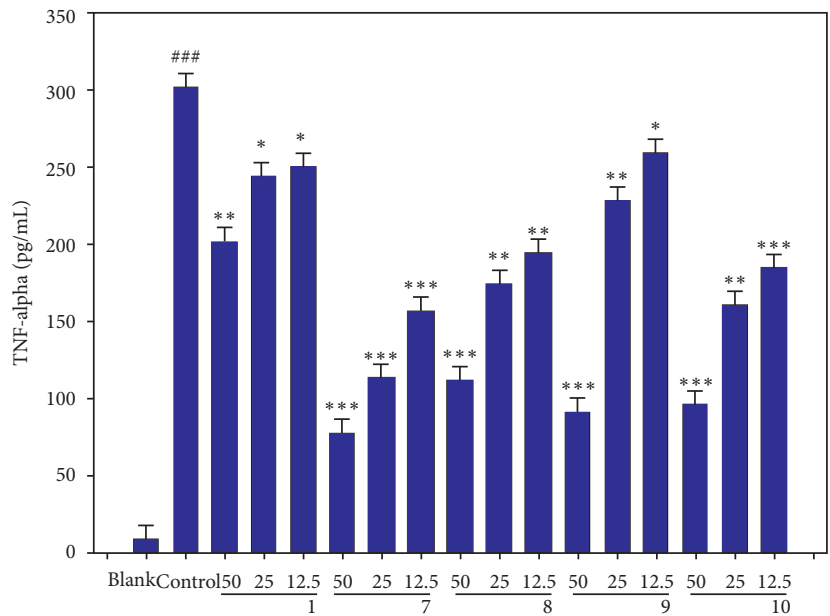

(d)

Figure 5: Effects of AS and FAS on IL-6 and TNF- $\alpha$ production in RAW 264.7 cells. (a) Effects of the A. sessiliflorus and FAS extracts on IL-6 production. (b) Effects of AS and FAS on TNF- $\alpha$ production. (c) Effects of the isolated compounds on IL-6 production. (d) Effects of the selected compounds on TNF- $\alpha$ production. The results are expressed as the mean \pm SD of triplicate experiments. \#\#\# $p<0.001$ when compared with the blank; ${ }^{* * *} p<0.001,{ }^{* *} p<0.01$, and ${ }^{*} p<0.05$ when compared with the control. 
TABLE 4: Effects of AS, FAS, and the selected compounds on the collagenase reaction.

\begin{tabular}{lccc}
\hline Extract $(25 \mu \mathrm{g} / \mathrm{mL})$ & Inhibition $(\%$ of control) & Extract $(50 \mu \mathrm{M})$ & Inhibition $(\%$ of control) \\
\hline AS & 33.00 & $\mathbf{1}$ & 15.38 \\
FAS & 79.00 & 7 & 23.08 \\
& & $\mathbf{8}$ & 22.12 \\
& & $\mathbf{9}$ & 90.38 \\
\hline
\end{tabular}

\section{Discussion}

There are many reports that the linkage of glycosyl groups of the aglycone can alter their bioactivities [27, 28]. The variation of natural products and their bioactivities by fermentation is also reported. For example, some researchers reported that rare ginsenosides could be produced from major ginsenosides by microorganisms [27, 29]. The aglycones of ginsenosides are more easily absorbed from the small intestine than glycosides and have altered physiological actions in vitro and in vivo [30, 31]. This has been reported for not only ginsenosides, but also other compounds, including tannins and fatty acids. L. plantarum subsp. argentoratensis has tannase and can decompose tannin; thus, it has been used for the initial degradation of complex tannins [32]. The fermentation of Vigna sinensis L., cowpea, increased phenolic compound content and enhanced antioxidant activity [33]. In another study, microorganisms converted linoleic and linolenic acids to unsaturated hydroxy fatty acids [34]. Syringaresinol, the aglycone form of lignan (7), has been reported to more strongly inhibit proinflammatory molecules (prostaglandin $\mathrm{E}_{2}$, TNF- $\alpha$, iNOS, and COX-2) compared with acanthoside $\mathrm{D}$, the glycoside form of lignan (1) [3]. In addition, caffeic acid, quinic acid, and protocatechuic acid, which are common in plants, have antioxidant, antitumor, and antiinflammatory activities [35]. In the present study, FAS showed stronger anti-inflammatory activities than AS. Moreover, the activity of syringaresinol (7) was better than that of acanthoside D (1). The HPLC analysis showed that the content of syringaresinol, the aglycone (7), increased during fermentation and the content of acanthoside D, the glycoside (1), decreased during fermentation. Protocatechuic acid (4) content also increased by bioconversion, and these compounds had good inhibitory effects on inflammatory-related factors. These results indicated that the variations due to bioconversion led to significant differences in the anti-inflammatory effects of the FAS and AS.

\section{Conclusion}

The biotransformation of the A. sessiliflorus extract via fermentation was performed. The inhibitions of the production of $\mathrm{NO}$ and inflammatory molecules by AS, FAS, and the isolated compounds were measured in vitro. The results showed that the content of the compounds was different in FAS and AS. The increased compounds, syringaresinol (7) and protocatechuic acid (4), showed better activity than acanthoside D (1). Moreover, the anti-inflammatory activities of FAS were stronger than those of AS. These results indicated that FAS and the isolated compounds may be a potential treatment for inflammatory disorders such as arthritis.

\section{Data Availability}

The data used to support the findings of this study are included within the article.

\section{Conflicts of Interest}

The authors declare that there are no conflicts of interest regarding the publication of this paper.

\section{Acknowledgments}

This research was supported by the Chung-Ang University Research Scholarship Grants in 2019. The authors would like to thank Editage (http://www.editage.co.kr) for English language editing. This work was supported by the National Research Foundation of Korea (NRF) grant funded by the Korea government (MSIT) (No. NRF-2020R1F1A1073407).

\section{Supplementary Materials}

Supplementary materials file includes NMR spectra of the 10 compound isolated from FAS. Figure S1-1: ${ }^{1} \mathrm{H}-\mathrm{NMR}$ spectrum of compound $1\left(600 \mathrm{MHz}, \mathrm{DMSO}+\mathrm{D}_{2} \mathrm{O}\right)$; Figure S1-2: ${ }^{13} \mathrm{C}-\mathrm{NMR}$ spectrum of compound $1(150 \mathrm{MHz}$, $\left.\mathrm{DMSO}+\mathrm{D}_{2} \mathrm{O}\right)$; Figure S2-1: ${ }^{1} \mathrm{H}-\mathrm{NMR}$ spectrum of compound $2\left(600 \mathrm{MHz}, \mathrm{DMSO}+\mathrm{D}_{2} \mathrm{O}\right)$; Figure $\mathrm{S} 2-2:{ }^{13} \mathrm{C}-\mathrm{NMR}$ spectrum of compound $2\left(150 \mathrm{MHz}, \mathrm{DMSO}+\mathrm{D}_{2} \mathrm{O}\right)$; Figure S3-1: ${ }^{1} \mathrm{H}-\mathrm{NMR}$ spectrum of compound $3(600 \mathrm{MHz}$, pyridine-d5); Figure S3-2: ${ }^{13} \mathrm{C}-\mathrm{NMR}$ spectrum of compound 3 (150 MHz, pyridine-d5); Figure S4-1: ${ }^{1} \mathrm{H}-\mathrm{NMR}$ spectrum of compound $4\left(600 \mathrm{MHz}, \mathrm{DMSO}+\mathrm{D}_{2} \mathrm{O}\right)$; Figure $\mathrm{S} 4-2:{ }^{13} \mathrm{C}$ NMR spectrum of compound $4\left(150 \mathrm{MHz}, \mathrm{DMSO}+\mathrm{D}_{2} \mathrm{O}\right)$; Figure S5-1: ${ }^{1} \mathrm{H}-\mathrm{NMR}$ spectrum of compound $5(600 \mathrm{MHz}$, $\left.\mathrm{DMSO}+\mathrm{D}_{2} \mathrm{O}\right)$; Figure S5-2: ${ }^{13} \mathrm{C}-\mathrm{NMR}$ spectrum of compound $5\left(150 \mathrm{MHz}, \mathrm{DMSO}+\mathrm{D}_{2} \mathrm{O}\right)$; Figure S6-1: ${ }^{1} \mathrm{H}-\mathrm{NMR}$ spectrum of compound $6\left(600 \mathrm{MHz}, \mathrm{DMSO}+\mathrm{D}_{2} \mathrm{O}\right)$; Figure S6-2: ${ }^{13} \mathrm{C}-\mathrm{NMR}$ spectrum of compound $6(150 \mathrm{MHz}$, $\mathrm{DMSO}+\mathrm{D}_{2} \mathrm{O}$ ); Figure S7-1: ${ }^{1} \mathrm{H}-\mathrm{NMR}$ spectrum of compound $7\left(600 \mathrm{MHz}, \mathrm{CDCl}_{3}\right)$; Figure $\mathrm{S} 7-2:{ }^{13} \mathrm{C}-\mathrm{NMR}$ spectrum of compound $7\left(150 \mathrm{MHz}, \mathrm{CDCl}_{3}\right)$; Figure S8-1: ${ }^{1} \mathrm{H}$ NMR spectrum of compound $8\left(600 \mathrm{MHz}, \mathrm{CDCl}_{3}\right)$; Figure S8-2: ${ }^{13} \mathrm{C}-\mathrm{NMR}$ spectrum of compound $8(150 \mathrm{MHz}$, $\left.\mathrm{CDCl}_{3}\right)$; Figure S9-1: ${ }^{1} \mathrm{H}-\mathrm{NMR}$ spectrum of compound 9 $\left(600 \mathrm{MHz}, \mathrm{CD}_{3} \mathrm{OD}+\mathrm{D}_{2} \mathrm{O}\right)$; Figure S9-2: ${ }^{13} \mathrm{C}-\mathrm{NMR}$ spectrum of compound $9\left(150 \mathrm{MHz}, \mathrm{CD}_{3} \mathrm{OD}+\mathrm{D}_{2} \mathrm{O}\right)$; Figure $\mathrm{S} 10-1$ : ${ }^{1} \mathrm{H}-\mathrm{NMR}$ spectrum of compound $10\left(600 \mathrm{MHz}, \mathrm{CDCl}_{3}\right)$; 
Figure S10-2: ${ }^{13} \mathrm{C}-\mathrm{NMR}$ spectrum of compound $\mathbf{1 0}$ $\left(150 \mathrm{MHz}, \mathrm{CDCl}_{3}\right)$. (Supplementary Materials)

\section{References}

[1] C. S. Yook, D. H. Lee, and Y. K. Seo, "A new forma of acanthopanx species (I)," Korean Journal of Anesthesiology, vol. 7, no. 3, pp. 179-190, 1976.

[2] M. Davydov and A. D. Krikorian, "Eleutherococcus senticosus (rupr. \& maxim.) maxim. (Araliaceae) as an adaptogen: a closer look," Journal of Ethnopharmacology, vol. 72, no. 3, pp. 345-393, 2000.

[3] H. J. Jung, H. J. Park, R. G. Kim et al., "In vivo anti-inflammatory and antinociceptive effects of liriodendrin isolated from the stem bark of Acanthopanax senticosus," Planta Medica, vol. 69, no. 7, pp. 610-616, 2003.

[4] L. Song, Y. Wu, L. Hu et al., Zhong Hua Ben Cao, Vol. 5, Shanghai Technology Press, Shanghai, China, 1999.

[5] K. Yoshizumi, K. Hirano, H. Ando et al., "Lupane-type saponins from leaves ofAcanthopanax sessiliflorusand their inhibitory activity on pancreatic lipase," Journal of Agricultural and Food Chemistry, vol. 54, no. 2, pp. 335-341, 2006.

[6] D.-Y. Lee, K.-H. Seo, R.-H. Jeong et al., "Anti-inflammatory lignans from the fruits of Acanthopanax sessiliflorus," Molecules, vol. 18, no. 1, pp. 41-49, 2012.

[7] D.-Y. Lee, K.-H. Seo, D.-S. Lee et al., "Bioactive 3,4-secotriterpenoids from the fruits of Acanthopanax sessiliflorus," Journal of Natural Products, vol. 75, no. 6, pp. 1138-1144, 2012.

[8] Y. Song, Y. Deng, D. Huang, J. Wen, Z. Liu, and F. Li, "LCMS/MS determination and pharmacokinetic study of four lignan components in rat plasma after oral administration of Acanthopanax sessiliflorus extract," Journal of Ethnopharmacology, vol. 141, no. 3, pp. 957-963, 2012.

[9] S. Lee, D. Son, J. Ryu et al., "Anti-oxidant activities ofacanthopanax senticosus stems and their lignan components," Archives of Pharmacal Research, vol. 27, no. 1, pp. 106-110, 2004.

[10] S.-Y. Lyu and W.-B. Park, "Modulation of IL-12 and IFN- $\gamma$ secretions by eleutheroside E, tortoside A, and syringaresinol from Acanthopanax koreanum nakai," Biomolecules and Therapeutics, vol. 18, no. 2, pp. 211-218, 2010.

[11] S. Chettibi, M. Ferguson, J. Gallin, and R. Snyderman, Inflammation: Basic Principles and Clinical Correlates, J. I. Gallin, S. R. Williams, and W. Lipincott, Eds., pp. 865-881, Raven Press, Philadelphia, PA, USA, 1999.

[12] M. B. Goldring, "Osteoarthritis and cartilage: the role of cytokines," Current Rheumatology Reports, vol. 2, no. 6, pp. 459-465, 2000.

[13] J. Yin, J. Heo, Y. Hwang, T. Le, and M. Lee, "Inhibitory activities of phenolic compounds isolated from adina rubella leaves against $5 \alpha$-reductase associated with benign prostatic hypertrophy," Molecules, vol. 21, no. 7, p. 887, 2016.

[14] H. G. Kim, K. Y. Kim, and C. J. Cha, "Screening for ginsengfermenting microorganisms capable of biotransforming ginsenosides," The Microbiological Society of Korea, vol. 43, no. 2, pp. 142-146, 2007.

[15] Y. Sawabe, K. Yamasaki, S. Iwagami, K. Kajimura, and K. Nakagomi, "Inhibitory effects of natural medicines on the enzymes related to the skin," Yakugaku Zasshi, vol. 118, no. 9, pp. 423-429, 1998.

[16] H. B. Park, K. H. Lee, K. H. Kim et al., "Lignans from the roots of Berberis amurensis," Natural Product Sciences, vol. 15, no. 1, pp. 17-21, 2009.
[17] N. Lami, S. Kadota, T. Kikuchi, and Y. Momose, "Constituents of the roots of Boerhaavia diffusa L. III. Identification of $\mathrm{Ca}^{2+}$ channel antagonistic compound from the methanol extract," Chemical \& Pharmaceutical Bulletin, vol. 39, no. 6, pp. 1551-1555, 1991.

[18] M. Lee, D. G. Lee, K. H. Lee et al., "Isolation and identification of phytochemical constituents from the fruits of Acanthopanax senticosus," African Journal of Pharmacy and Pharmacology, vol. 7, no. 6, pp. 294-301, 2013.

[19] L. J. An, S. Guan, G. F. Shi, Y. M. Bao, Y. L. Duan, and B. Jiang, "Protocatechuic acid from Alpinia oxyphylla against MPP+ induced neurotoxicity in PC12 cells," Food and Chemical Toxicology, vol. 44, no. 3, pp. 436-443, 2006.

[20] H. A. Jung, J. C. Park, H. Y. Chung, J. Kim, and J. S. Choi, "Antioxidant flavonoids and chlorogenic acid from the leaves of Eriobotrya japonica," Archives of Pharmacal Research, vol. 22, no. 2, pp. 213-218, 1999.

[21] L. Wu, J. Zheng, B. Jiang et al., "Chemical constituents of the stems and leaves of Acanthopanax senticosus (rupr, ET maxim.) harms," Acta Pharmaceutica Sinica, vol. 34, pp. 294-296, 1999.

[22] T. Deyama, T. Ikawa, and S. Nishibe, "The constituents of Eucommia ulmoides Oliv. II. Isolation and structures of three new lignan glycosides," Chemical \& Pharmaceutical Bulletin, vol. 33, no. 9, pp. 3651-3657, 1985.

[23] P. Bradesi, F. Tomi, and J. Casanova, "Carbon-13 NMR study of farnesol, farnesyl acetate and farnesal stereoisomers: chemical shift assignment using lanthanide induced shifts," Canadian Journal of Applied Spectroscopy, vol. 40, no. 3, pp. 76-81, 1995.

[24] M. Miyazawa, H. Nankai, and H. Kameoka, "Biotransformation of acyclic terpenoid (2E,6E)-farnesol by plant pathogenic fungus Glomerella cingulata," Phytochemistry, vol. 43, no. 1, pp. 105-109, 1996.

[25] P. Basnet, K. Matsushige, K. Hase, S. Kadota, and T. Namba, "Four di-O-caffeoyl quinic acid derivatives from propolis. Potent hepatoprotective activity in experimental liver injury models," Biological \& Pharmaceutical Bulletin, vol. 19, no. 11, pp. 1479-1484, 1996.

[26] T. Fujioka, K. Furumi, H. Fujii et al., "Antiproliferative constituents from umbelliferae plants. V. A new furanocoumarin and falcarindiol furanocoumarin ethers from the root of Angelica japonica," Chemical \& Pharmaceutical Bulletin, vol. 47, no. 1, pp. 96-100, 1999.

[27] Y.-Y. Wu, Y.-N. Cui, T.-Y. Zhang et al., "Transformation of ginsenoside Rh4 and its aglycone from the total saponins of stems and leaves of Panax ginseng by Aspergillus tubingensis," Phytochemistry Letters, vol. 27, pp. 123-128, 2018.

[28] J. S. Park, H. S. Rho, D. H. Kim, and I. S. Chang, "Enzymatic preparation of kaempferol from green tea seed and its antioxidant activity," Journal of Agricultural and Food Chemistry, vol. 54, no. 8, pp. 2951-2956, 2006.

[29] Y. Fu, Z. H. Yin, and C. Y. Yin, "Biotransformation of ginsenoside $\mathrm{Rb} 1$ to ginsenoside Rg3 by endophytic bacterium Burkholderia sp. GE 17-7 isolated from Panax ginseng," Journal of Applied Microbiology, vol. 122, no. 6, pp. 1579-1585, 201.

[30] C. Hu, G. Song, B. Zhang et al., "Intestinal metabolite compound $\mathrm{K}$ of panaxoside inhibits the growth of gastric carcinoma by augmenting apoptosis via Bid-mediated mitochondrial pathway," Journal of Cellular and Molecular Medicine, vol. 16, no. 1, pp. 96-106, 2012.

[31] E.-H. Joh, I.-A. Lee, I.-H. Jung, and D.-H. Kim, “Ginsenoside $\mathrm{Rb} 1$ and its metabolite compound $\mathrm{K}$ inhibit IRAK-1 
activation-the key step of inflammation," Biochemical Pharmacology, vol. 82, no. 3, pp. 278-286, 2011.

[32] N. Jiménez, M. Esteban-Torres, J. M. Mancheño, B. de las Rivas, and R. Muñoz, "Tannin degradation by a novel tannase enzyme present in some Lactobacillus plantarum strains," Applied and Environmental Microbiology, vol. 80, no. 10, pp. 2991-2997, 2014.

[33] M. Dueñas, D. Fernández, T. Hernández, I. Estrella, and R. Muñoz, "Bioactive phenolic compounds of cowpeas (Vigna sinensisL). Modifications by fermentation with natural microflora and with Lactobacillus plantarum ATCC 14917," Journal of the Science of Food and Agriculture, vol. 85, no. 2, pp. 297-304, 2005.

[34] S. Koritala and M. O. Bagby, "Microbial conversion of linoleic and linolenic acids to unsaturated hydroxy fatty acids," Journal of the American Oil Chemists' Society, vol. 69, no. 6, pp. 575-578, 1992.

[35] C.-L. Liu, J.-M. Wang, C.-Y. Chu, M.-T. Cheng, and T.-H. Tseng, "In vivo protective effect of protocatechuic acid on tert-butyl hydroperoxide-induced rat hepatotoxicity," Food and Chemical Toxicology, vol. 40, no. 5, pp. 635-641, 2002. 